\title{
Na Onda do Pitiú: Uma Abordagem de Educação Ambiental Gamificada no Contexto Amazônico
}

\author{
Benedito de Souza Ribeiro Neto ${ }^{1}$, Alan Barros Virgolino ${ }^{1}$ \\ Daví Araújo Ferreira ${ }^{1}$, Marcus Vinicius Brito da Silva ${ }^{1}$ \\ ${ }^{1}$ Instituto Federal de Educação, Ciência e Tecnologia do Pará (IFPA) - Campus Cametá \\ Av. Gentil Bittencourt, 1580 - 68400-000 - Cametá - PA - Brasil \\ \{benedito.neto, marcus.brito\}@ifpa.edu.br
}

\begin{abstract}
The goal of this study is to demonstrate the development of an educational game in the perspective of Amazonian environmental education, using as a development tool the Scratch platform through a simple programming language. The study was carried out with 32 students from the 4th and 5th-grade classes of the Elementary School of General Osório, located in the municipality of Cametá-Pará, Brazil. The results show that more than $90 \%$ of the students report a higher concentration and immersion in the content when they use the digital game as an auxiliary tool in the learning process. The educational game made possible the practice of the intellect, attention, power of analysis, awakening of the imagination and other dimensions of the human being, as well as the sensitization about the selective garbage collection in the Tocantins river, providing a more pleasant education.
\end{abstract}

Resumo. O presente estudo tem como objetivo demonstrar o desenvolvimento de um jogo educativo na perspectiva da educação ambiental Amazônica, utilizando como ferramenta de desenvolvimento a plataforma Scratch por meio de uma linguagem de programação simples. O trabalho foi desenvolvido com 32 discentes de turmas do $4^{\circ}$ e $5^{\circ}$ ano do Ensino Fundamental da Escola Municipal de Ensino Fundamental General Osório, situada no município de Cametá-Pará, Brasil. Os resultados obtidos apontam que mais de $90 \%$ dos alunos relatam maior concentração e imersão no conteúdo abordado, quando utilizam o jogo digital como ferramenta auxiliar no processo de aprendizagem. O jogo educativo possibilitou a prática do intelecto, atenção, poder de análise, despertar da imaginação e outras dimensões próprias do ser humano, além da sensibilização sobre a coleta seletiva de lixo de maneira gamificada no rio Tocantins, propiciando uma educação mais prazerosa.

\section{Introdução}

Atualmente as diretrizes educacionais brasileiras, buscam o desenvolvimento de processos educacionais eficientes que contribuam para uma formação de professores e alunos, baseados em fatos do cotidiano. Esses processos abordam os aspectos sociais, culturais, econômicos e naturais, visando o bem estar da sociedade e do meio ambiente em que vive através da educação ambiental. A educação ambiental pode ser descrita como uma modalidade específica de educação, como um processo contínuo, participativo e transversal que envolve escola, família e sociedade. E, além disso, atravessa diversas disciplinas, como ciências, geografia e biologia e envolve o aprendizado formal e informal [MEC 2001]. 
VIII Congresso Brasileiro de Informática na Educação (CBIE 2019)

Anais do XXX Simpósio Brasileiro de Informática na Educação (SBIE 2019)

Por outro lado, a problemática do lixo urbano vem sendo agravada, entre outros fatores, pelo acentuado crescimento demográfico, especialmente nos centros urbanos, resultantes do êxodo rural e da falta de planejamento urbano. Logo, a proposta da coleta seletiva do lixo é uma ação educativa que visa investir em uma mudança de mentalidade como um elo para trabalhar a transformação da consciência ambiental [Felix 2007]. A gamificação na educação ambiental, por sua vez, corresponde ao uso de mecanismos de jogos, tais como competição, desafio, interação social e recompensa, em contextos não relacionados a jogos [Kapp 2012]. Assim, o uso de ferramentas gamificadas implicam em empregar as mesmas estratégias, elementos e métodos utilizados em jogos, para resolver problemas que não estão associados aos jogos, mas que estão associados à ações comuns do mundo real [Ribeiro et al. 2018].

Para Falcão (2014) os jogos educacionais estão sendo cada vez mais utilizados no processo de ensino-aprendizagem [Falcão et al. 2014]. O uso do computador como ferramenta educacional tem sido visto como uma alternativa que permite adquirir um aprendizado por meio da resolução de problemas e da comunicação, propiciando uma educação mais prazerosa [Sabino 2014]. O pensamento computacional (PC), por sua vez, é definido como processo que envolve a formulação de um problema. Papert (1980) propõe que se o indivíduo utilizar meios computacionais para criação da sua aprendizagem, visualizará seus produtos e conseguirá estabelecer uma relação entre o concreto e o abstrato [Papert et al. 1980]. É na abstração que está a maior força do pensamento computacional [Wing 2017].

Nesta perspectiva, este trabalho demonstra um jogo educativo na perspectiva da educação ambiental no contexto Amazônico. Para seu desenvolvimento, foi utilizada como ferramenta a plataforma Scratch [Resnick et al. 2009], que permite criar animações, histórias interativas e até mesmo jogos por meio de uma linguagem de programação simples e amigável. O jogo, denominado "Na onda do Pitiú" introduz o personagem "Pitiú", apelido dado ao peixe da espécie Mapará (Hypophthalmus edentatus), abundante na região do baixo Tocantins. O personagem incentiva o usuário a recolher o lixo espalhado pelo rio e ajudá-lo a se defender dos vários desafios da região, como a poluição, peixes predadores, além das armadilhas de pesca.

Para o processo de avaliação e validação da proposta deste trabalho, o jogo "Na onda do Pitiú" foi aplicado a alunos de uma escola do ensino básico na cidade de CametáPA, no interior do estado do Pará, localizada na já mencionada região do baixo Tocantins. Desse modo, foi possível mensurar qualitativamente a contribuição da proposta quanto ao conhecimento transmitido para os alunos do $4^{\circ}$ e $5^{\circ}$ ano do ensino fundamental. Os resultados obtidos apontam que mais de $90 \%$ dos alunos relatam maior concentração e imersão no conteúdo abordado, quando utilizam o jogo digital como ferramenta para auxiliar na aprendizagem.

A organização deste trabalho segue com os trabalhos relacionados na Seção 2. A Seção 3 descreve o pensamento computacional e a plataforma SCRATCH. A Seção 4 descreve a metodologia empregada no desenvolvimento da proposta apresentada. A Seção 5 apresenta o jogo educativo proposto neste trabalho. A Seção 6 destaca a avaliação da ferramenta e os resultados obtidos. Por fim, na Seção 7 são apresentadas algumas considerações sobre o trabalho realizado e propostas para trabalhos futuros. 
VIII Congresso Brasileiro de Informática na Educação (CBIE 2019)

Anais do XXX Simpósio Brasileiro de Informática na Educação (SBIE 2019)

\section{Trabalhos Relacionados}

Nesta seção são apresentados alguns trabalhos relacionados à proposta desse estudo. Inicialmente são destacados os trabalhos que abordam diretamente a temática de conscientização ambiental, fazendo uso de jogos digitais. Na sequencia, é apresentado um trabalho que explora os recursos da plataforma $S C R A T C H$ para auxiliar o ensino e aprendizagem de conteúdos de física básica.

No trabalho de Nunes e Chaves (2017) foi desenvolvido o jogo Ciano Quiz [Nunes and Chaves 2017] de perguntas e respostas com enfoque na Educação ambiental, voltado para alunos do Ensino Médio. Seu principal objetivo está em conscientizar e informar os alunos sobre os impactos no meio ambiente e na saúde humana, destacando o problema da contaminação das águas com cianobactérias. Já Souza Jr (2009), apresenta um jogo lúdico que busca apenas a identificação dos elementos característicos do lixo. A interface do jogo faz uso da realidade aumentada para inserir numa cena real capturada pela webcam [Souza Jr et al. 2009]. Com essa dinâmica, é possível reforçar o conceito de lixo reciclável e como a separação deve ser feita, nas lixeiras corretas. Através deste jogo, as crianças memorizam cada tipo de lixo com a respectiva cor para cada tipo de lixo reciclável.

Hinterholz (2010) apresenta o jogo TerraEdu do gênero Serious Game 3D [Hinterholz et al. 2010] que tem por objetivo ser uma ferramenta para auxiliar no processo de Educação Ambiental para adolescentes do $6^{\circ}$ e $7^{\circ}$ ano do ensino fundamental, de escolas públicas. Dentro do contexto turístico, da fauna e flora do Estado de Roraima, o jogo apresenta uma abordagem pedagógica construcionista e humanista, que visa contribuir com a educação ambiental de forma lúdica e interativa. O jogo, Jogando Verde [Santos et al. 2016], por sua vez, aborda os impactos ambientais causados pelo setor agropecuário, a partir de missões fundamentadas nos componentes curriculares do Curso Técnico em Agropecuária do Instituto Federal de Educação, Ciência e Tecnologia Baiano - IF Baiano, campus Teixeira de Freitas.

Em "Ondulatória" [Franzoia et al. 2018], os autores apresentam uma abordagem para auxiliar o processo de ensino e aprendizagem dos conteúdos de física básica, mais precisamente, sobre ondulatória, utilizando a plataforma SCRATCH [Resnick et al. 2009]. Além estimular o aprendizado das temáticas de ondulatória, a ferramente também serviu como estímulo à construção de um pensamento computacional aos alunos do Ensino Médio. O projeto consistiu em introduzir a plataforma SCRATCH para que os alunos do ensino médio implementassem eventos e comportamento digitais que simulassem os fenômenos de cinemática. Após a introdução da plataforma SCRATCH, foi perceptível o aumento não só nas notas dos alunos, mas também no aproveitamento e desenvolvimento do pensamento computacional.

De modo geral, esses trabalhos descrevem a atual e relevante discussão sobre as temáticas relacionadas aos cuidados com o meio ambiente, bem como as propostas que utilizam recursos computacionais para ludificar o processo de ensino e aprendizagem. No entanto, ainda que seja evidente a importância dos trabalhos que discorrem sobre os cuidados ambientais utilizando ferramentas computacionais, no melhor dos nossos conhecimentos, não foram encontradas propostas que combinam jogos digitais, a partir da plataforma SCRATCH, voltada à educação ambiental no contexto Amazônico, como o apresentado neste trabalho. 
VIII Congresso Brasileiro de Informática na Educação (CBIE 2019)

Anais do XXX Simpósio Brasileiro de Informática na Educação (SBIE 2019)

\section{O pensamento Computacional}

O pensamento computacional (PC) é definido como processo envolvido na formulação de um problema, expressando sua solução de uma maneira que um computador ou humano possam realizar [Wing and Stanzione 2016]. Ou seja, é uma nova abordagem da Teoria Cognitiva, ligada às rubricas da Ciência da Computação, a partir da compreensão de que quanto mais cedo se desenvolve o PC, maiores as possibilidades de lidar com a resolução de problemas de ordem complexa. Estes, por sua vez, que podem ou não ser resolvidos a partir das novas tecnologias digitais, ou desenvolvimento de outras, tendo quatro pilares básicos como fundamento: Decomposição, Padrão, Abstração e Algoritmo [Wing 2017].

Papert (1980) propõe que se o indivíduo utilizar meios computacionais para criação da sua aprendizagem, visualizará seus produtos e conseguirá estabelecer uma relação entre o concreto e o abstrato [Papert et al. 1980]. É na abstração que está a maior força do pensamento computacional [Wing 2017]. A partir da produção de tecnologias próprias para aprendizagem, gerar conhecimento tanto na pesquisa aplicada ao processo da ação, quanto no processo construtivo dessas tecnologias, em ambos os casos o indivíduo está exposto a resolução de problemas [Reis 2007].

\subsection{A Plataforma SCRATCH}

Segundo Resnick (2009) a plataforma de desenvolvimento Scratch é uma ferramenta criada no Media Laboratory of Massachusetts Institute of Technology (MIT), sendo a mais recente de uma longa linhagem de ferramentas que se iniciou com a criação da linguagem de programação LOGO. No Scratch, os usuários não tem que se preocupar com erros de sintaxe, pois os blocos de programação se encaixam apenas quando há sentido, sintaticamente. Além disso, a plataforma possui uma linguagem de fácil aprendizado, possibilitando a criação de histórias interativas, animações, jogos, músicas e o compartilhamento dessas criações na Internet [Resnick et al. 2009].

De acordo com [Maloney et al. 2008], Scratch apoia e promove o desenvolvimento de nove competências de aprendizagem :

- Competências no gerenciamento de informações em diversas mídias;

- Competências de comunicação;

- Raciocínio crítico e pensamento sistemático;

- Identificação, formulação e resolução de problemas;

- Criatividade e curiosidade intelectual;

- Competências interpessoais e de colaboração;

- Autonomia;

- Responsabilidade e Adaptabilidade;

- Responsabilidade Social.

\section{Metodologia}

Ao alcance do objetivo deste trabalho, buscou-se estrategicamente, trilhar as seguintes ações em seu desenvolvimento, de acordo com a metodologia ilustrada na Figura 1.

- Analise de requisitos: identificação dos problemas ambientais do município de Cametá - PA, com as devidas proposições de soluções tecnológicas e educacionais, além da identificação das funcionalidades do jogo, cenários e atores; 
VIII Congresso Brasileiro de Informática na Educação (CBIE 2019)

Anais do XXX Simpósio Brasileiro de Informática na Educação (SBIE 2019)

- Planejamento do Roteiro do jogo: construção de uma história com apresentação, evolução e encerramento que retrate o contexto da educação ambiental no município de Cametá;

- Projeto lógico: desenvolvimento de diagramas, demonstrando todos os aspectos estruturais e comportamentais do jogo;

- Desenvolvimento: confecções dos cenários, atores, funcionalidades e rotinas;

- Teste: realização de teste unitário e de integração;

- Avaliação: avaliação de usabilidade, ergonomia e interface gráfica do jogo por alunos da EMEF General Osório.

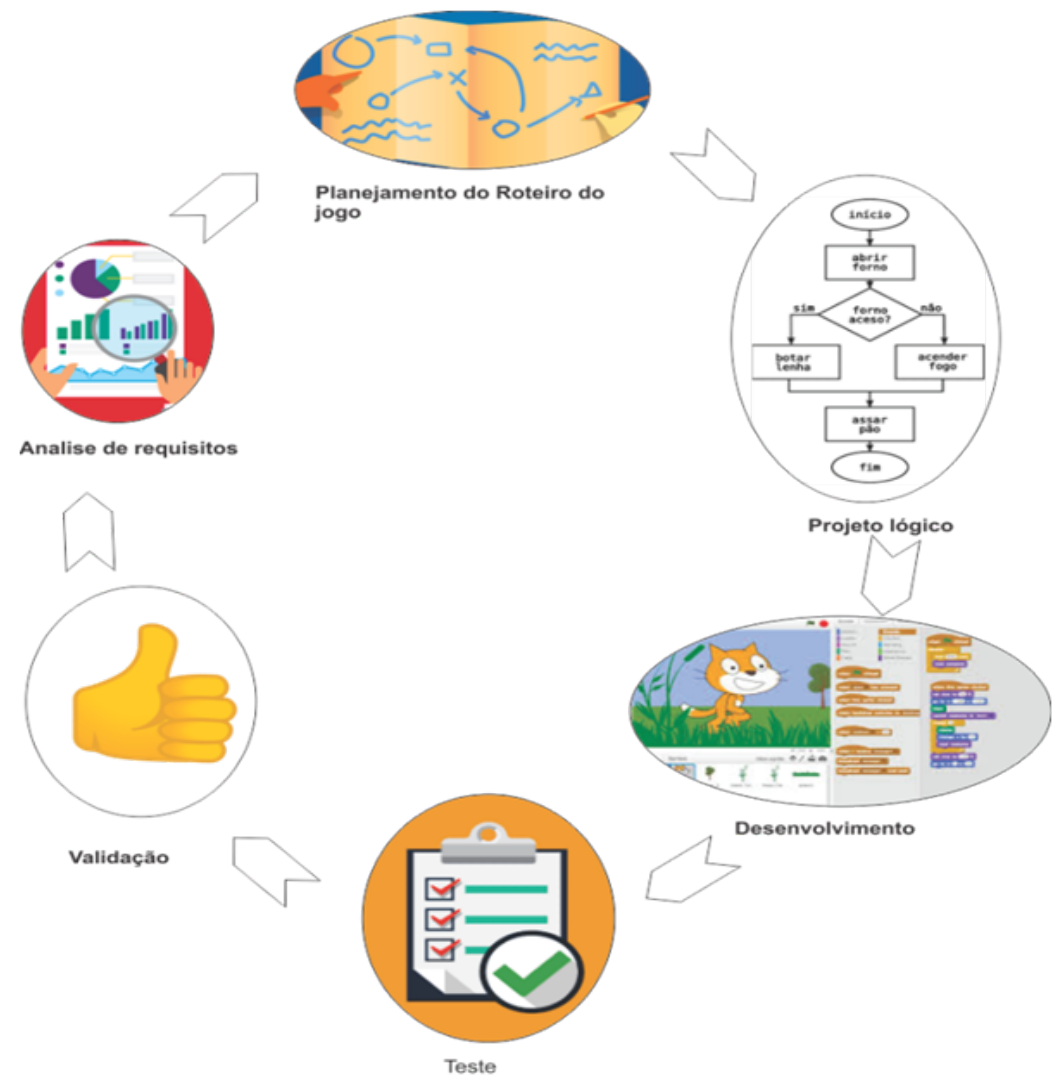

Figura 1. Ilustração da metodologia adotada.

\subsection{Local e Sujeitos da Pesquisa}

Cametá é um município histórico que teve seu povoamento a partir de 1620, entretanto, apenas em 1635 ocorreu sua ascensão à categoria de município com a fixação de habitantes na margem esquerda do rio Tocantins. O município é formado por mais de 150 ilhas comportando $70 \%$ da população que utilizam os rios como via de transporte e fonte de trabalho e renda.

O projeto deste trabalho foi desenvolvido ao longo do ano de 2018 com 72 alunos de turmas de $4^{\circ}$ e $5^{\circ}$ ano do Ensino Fundamental da Escola Municipal de Ensino Fundamental General Osório, situada no município de Cametá -Pará, Brasil. A presente intervenção pedagógica teve o intuito de sensibilizar os alunos quanto à preservação do rio Tocantins, utilizando um personagem da alimentação local, o peixe Mapará (Hypophthalmus edentatus), abundante na região do baixo Tocantins. 
VIII Congresso Brasileiro de Informática na Educação (CBIE 2019)

Anais do XXX Simpósio Brasileiro de Informática na Educação (SBIE 2019)

\section{O Jogo na Onda do Pitiú}

$\mathrm{O}$ jogo tem o intuito de promover bons hábitos e o cuidado com o rio Tocantins. $\mathrm{O}$ usuário deverá fazer com que o personagem "Pitiú", apelido dado ao peixe da espécie mapará (Hypophthalmus edentatus) abundante na região do baixo Tocantins, recolha o lixo espalhado no meio do rio. Além disso, o personagem "Pitiú" deve se defender dos vários desafios da região como a poluição, peixes predadores, além das armadilhas de pesca dos pescadores, conforme é mostrada na Figura 2.

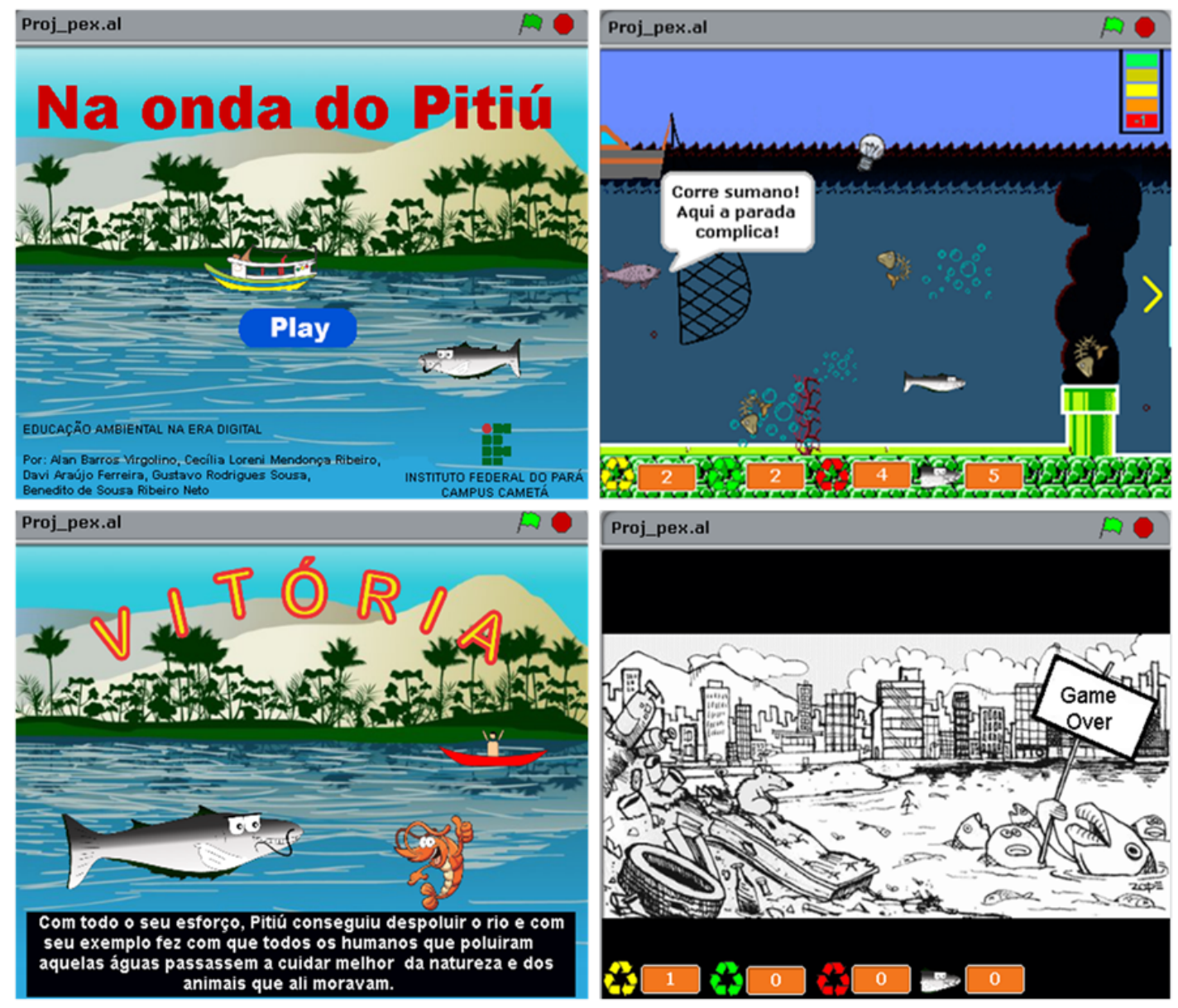

Figura 2. llustração das telas do jogo.

Os cenários do game são uma visualização de um ambiente aquático com peixes e diferentes obstáculos entre as dez fases que compreendem o jogo. Dentro dessas, encontram-se três tipos de lixo no fundo rio Tocantins (metal, plástico e vidro), que podem ser diversos tipos de objetos espalhados pelos caminhos, os quais o personagem Pitiú e outros predadores podem encostar. O jogador deve recolher o lixo que encontrar ao longo do jogo para descartá-lo corretamente na última fase.

O jogador apenas chegará ao final do jogo se conseguir coletar todo o lixo no rio, mas só vencerá se durante a fase final ( $10^{\mathrm{a}}$ fase) descartar tudo corretamente. Caso o jogador toque em algum peixe, armadilha ou molusco, uma penalidade é aplicada e este perderá "uma vida". Se o jogador perder um total de cinco vidas, como resultado, perde-se o jogo. Caso o jogador consiga recolher e descartar o lixo ao longo das fases 
VIII Congresso Brasileiro de Informática na Educação (CBIE 2019)

Anais do XXX Simpósio Brasileiro de Informática na Educação (SBIE 2019)

sem perder todas as vidas, ganha-se o jogo. Todas as funcionalidades foram testadas de forma unitária e de forma integrada para eliminação de erros de semântica.

O Diagrama de atividades (Figura 3), gerado na fase de projeto lógico, demonstra as transições entre as telas do jogo e os efeitos causados pelas tomadas de decisões do jogador. Inicialmente é apresentada uma tela inicial e de introdução com as principais informações e considerações. Na sequência, o jogador dá início as fases do game educativo. A cada fase realizada com sucesso, uma nova é habilitada e um incremento na dificuldade é empregado. Ao concluir com sucesso a décima fase, uma tela de vitória é apresentada como ilustrado na figura inferior esquerda (Figura 2). Se o jogador não obter sucesso em qualquer fase, uma tela de fim de jogo é apresentada (Game Over), como ilustra a figura inferior direita (Figura 2).

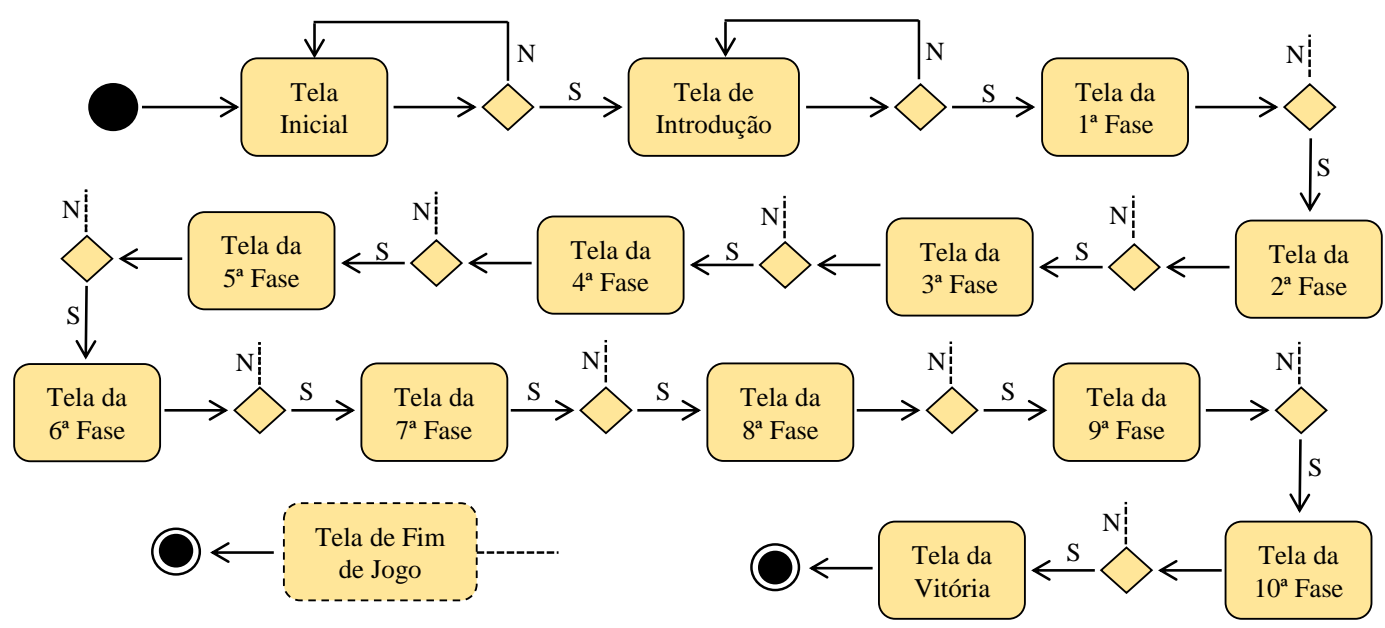

Figura 3. Diagrama de atividades do jogo.

\section{Avaliação}

Essa seção descreve o processo empregado para a avaliação da ferramenta apresentada neste trabalho, o jogo "Na onda do Pitiú". A avaliação foi dividida em duas etapas principais. Primeiro foi realizado um processo de aquisição do conhecimento para observar o perfil dos alunos na escola avaliada. Na sequencia, o jogo "Na onda do Pitiú" foi introduzido aos alunos e questionários foram aplicados para avaliar a usabilidade da ferramenta, tal como descrito a seguir.

\subsection{Processo de aquisição do conhecimento}

Inicialmente foi aplicado um questionário estruturado com o objetivo de analisar o perfil dos alunos da escola General Osório a respeito da coleta seletiva. A partir do questionário, foi identificado que $47 \%$ dos alunos não tinham conhecimento algum sobre o descarte de metal, papel, plástico, vidro e o lixo orgânico. Um percentual de $25 \%$ alegaram apresentar pouco conhecimento sabendo sobre o descarte de metal e lixo orgânico, $20 \%$ alegaram ter conhecimento mediano, só sabem fazer o descarte de metais, lixo orgânico e vidro. Por fim, um percentual de apenas $8 \%$ alegaram conhecimento total sobre o descarte adequado do lixo conforme o gráfico, ilustrado na Figura 4. 
VIII Congresso Brasileiro de Informática na Educação (CBIE 2019)

Anais do XXX Simpósio Brasileiro de Informática na Educação (SBIE 2019)

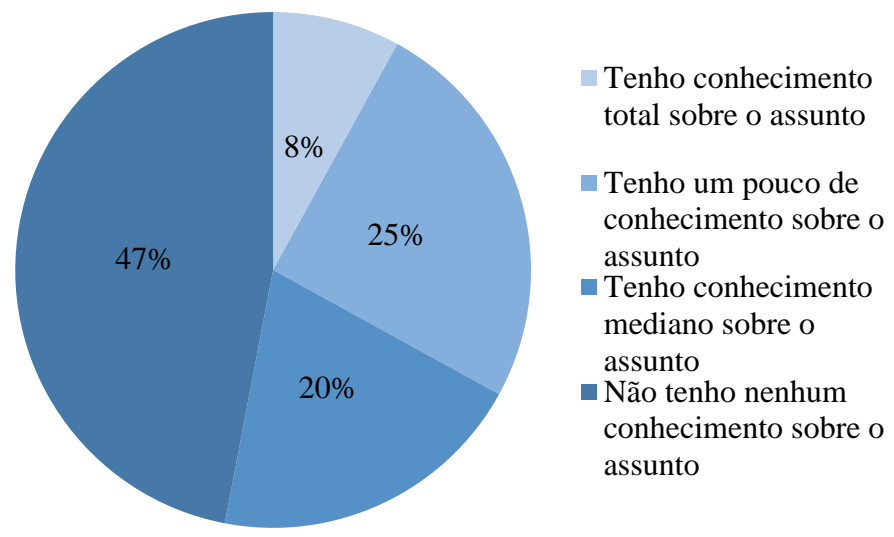

Figura 4. Níveis de conhecimento dos alunos sobre coleta seletiva.

\subsection{Resultados}

Foram aplicados questionários estruturados para a validação da usabilidade e Gamificação com 72 alunos do $4^{\circ}$ e $5^{\circ}$ ano do ensino fundamental (Figura 5) para qualificação do jogo, utilizando o método gameflow utilizado por [Neves et al. 2014] e por [Pires et al. 2018] para verificar a imersão do jogador e se os requisitos de gamificação e aprendizagem poderiam ser alcançados. A Figura 5 ilustra a aplicação do jogo $\mathrm{Na}$ Onda do Pitiú para os alunos da Escola Municipal de Ensino Fundamental General Osório em Cametá-PA.
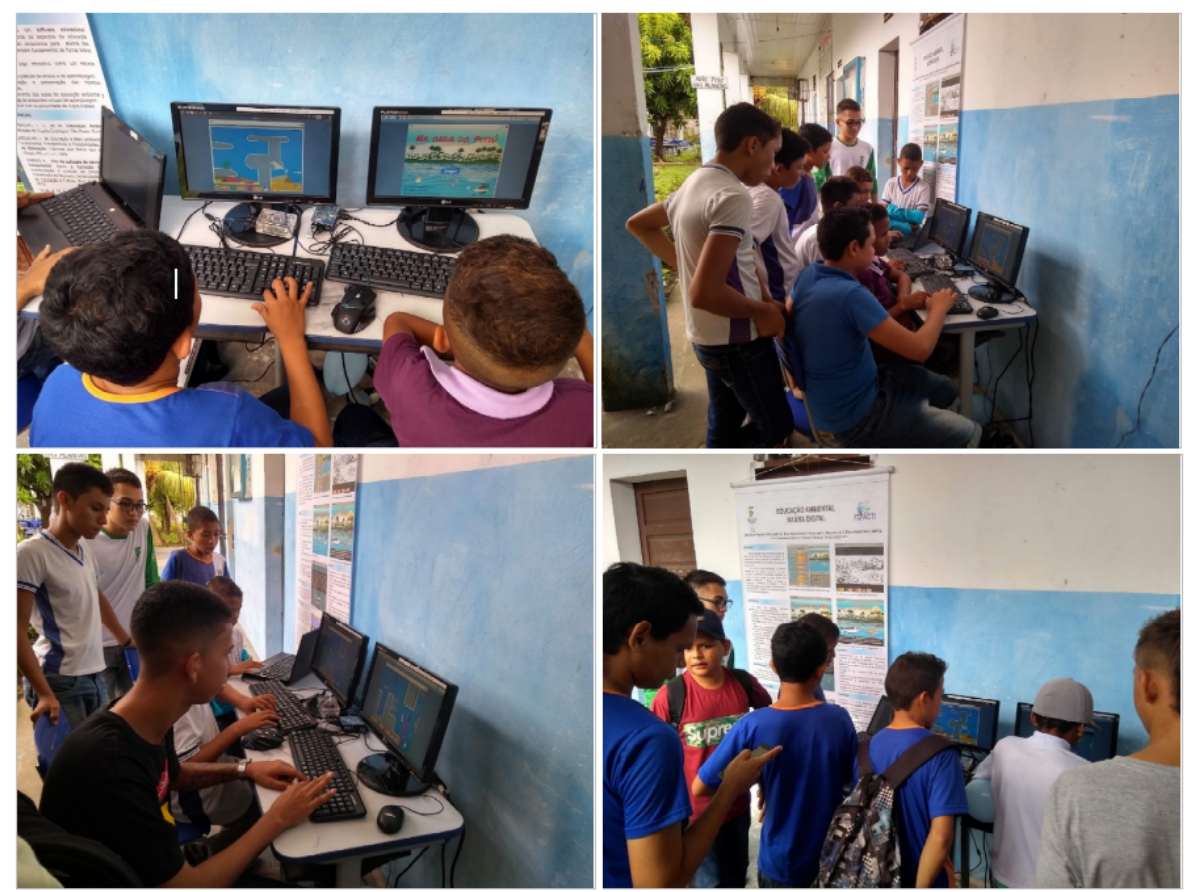

Figura 5. Avaliação da usabilidade do jogo na Escola Municipal de Ensino Fundamental General Osório em Cametá-PA.

Para a gamificação, o jogo foi incorporado nos elementos dinâmica, mecânica e componentes do jogo definidos por Alves [2015] para o contexto amazônico. Os resultados levaram em conta as notas distribuídas da seguinte forma: $0=$ não se aplica, $1=$ 
VIII Congresso Brasileiro de Informática na Educação (CBIE 2019)

Anais do XXX Simpósio Brasileiro de Informática na Educação (SBIE 2019)

deveria ter, mas não tem, 2 = ruim, $3=$ médio, 4 = bom. No questionário considerou 7 princípios: concentração, desafio, habilidades do jogador, controle, objetivos, feedback e imersão. Os resultados podem ser visualizados na Tabela 1, abaixo.

Tabela 1. Resultados GameFlow

\begin{tabular}{lccccc}
\hline Critérios & 0 - Não se aplica & $\begin{array}{l}\text { 1 - Deveria ter, } \\
\text { mas não tem }\end{array}$ & 2 - Ruim & 3 - Moderado & 4 - Bom \\
\hline Concentração & $7 \%$ & $0 \%$ & $0 \%$ & $44 \%$ & $49 \%$ \\
Desafio & $0 \%$ & $0 \%$ & $0 \%$ & $56 \%$ & $44 \%$ \\
Habilidades & $10 \%$ & $6 \%$ & $1 \%$ & $40 \%$ & $43 \%$ \\
do jogador & $6 \%$ & $4 \%$ & $0 \%$ & $31 \%$ & $60 \%$ \\
Controle & $0 \%$ & $0 \%$ & $0 \%$ & $53 \%$ & $47 \%$ \\
Objetivos & $0 \%$ & $0 \%$ & $0 \%$ & $42 \%$ & $58 \%$ \\
Feedback & $0 \%$ & $0 \%$ & $0 \%$ & $54 \%$ & $46 \%$ \\
Imersão & & & & &
\end{tabular}

Em síntese, os resultados descritos na Tabela 1 apontam que pelo menos 90\% dos alunos que tiveram contato com o jogo relatam ter concentração e imersão boa ou moderada à temática apresentada, quando utilizam a ferramenta.

\section{Considerações Finais}

O presente trabalho apresentou o desenvolvimento de um jogo para educação ambiental no contexto amazônico da região do Baixo Tocantins, denominado " $\mathrm{Na}$ Onda do Pitiú". O objetivo deste trabalho é sensibilizar alunos do ensino fundamental sobre a coleta seletiva de lixo no rio Tocantins, utilizando uma estratégia gamificada. Os resultados apontam uma imersão de pelo menos $90 \%$ dos alunos à temática apresentada, quando utilizam o jogo como ferramenta auxiliar no processo de aprendizado e conscientização. Como continuação deste trabalho educativo, será desenvolvida uma nova temática sobre o personagem Pitiú, afim de reforçar a alfabetização de crianças ribeirinhas no município de Cametá - Pa, utilizando a construção de palavras do cotidiano.

\section{Referências}

Falcão, T. P., Santos, R., Rodrigues, A., and Silva, P. (2014). Corpo e mente: uma análise educacional e de usabilidade da interação corporal em jogos de videogame. In Proceedings of the 13th Brazilian Symposium on Human Factors in Computing Systems, pages 150-159. Sociedade Brasileira de Computação.

Felix, R. A. Z. (2007). Coleta seletiva em ambiente escolar. REMEA-Revista Eletrônica do Mestrado em Educação Ambiental, 18.

Franzoia, F., de Sousa Pires, F. G., Teixeira, K. B., and Lima, P. (2018). Programando para criar objetos de aprendizagem digitais de Ondulatória. In Brazilian Symposium on Computers in Education (Simpósio Brasileiro de Informática na Educação-SBIE), volume 29, page 1063.

Hinterholz, O., Pereira, J. I. B., Silva, W. A., da Silva, E. M., Alves, R. L., Francisco de Assis, M. P., Valenzuela, G. M., and Freire, A. A. C. (2010). TERRAEDU: uma Abordagem Baseada em Jogos para a Educação Ambiental na Amazônia. 
VIII Congresso Brasileiro de Informática na Educação (CBIE 2019)

Anais do XXX Simpósio Brasileiro de Informática na Educação (SBIE 2019)

Kapp, K. M. (2012). The gamification of learning and instruction. Wiley San Francisco.

Maloney, J. H., Peppler, K., Kafai, Y., Resnick, M., and Rusk, N. (2008). Programming by choice: urban youth learning programming with scratch, volume 40. ACM.

MEC, B. S. d. E. F. (2001). Parametros curriculares nacionais: meio ambiente, saude. MEC, SEF.

Neves, D. E., de Oliveira Santos, L. G. N., Santana, R. C., and Ishitani, L. (2014). Avaliação de jogos sérios casuais usando o método GameFlow. Revista Brasileira de Computação Aplicada, 6(1):45-59.

Nunes, P. R. and Chaves, A. C. L. (2017). Ciano quiz: um jogo digital sobre cianobactérias como intrumento para a educação ambiental no ensino médio. Revista Ciências \& Ideias ISSN: 2176-1477, 7(3):324-349.

Papert, S., Valente, J. A., and Bitelman, B. (1980). Logo: computadores e educação. Brasiliense.

Pires, F. G. d. S., da Silva Queroga, J., Pessoa, M. S. P., and Melo, R. (2018). A Viagem: Um jogo para explorar o território Brasileiro. In Brazilian Symposium on Computers in Education (Simpósio Brasileiro de Informática na Educação-SBIE), volume 29, page 705 .

Reis, M. F. d. C. T. (2007). A pesquisa-ação-participativa em educação ambiental: reflexões teóricas. Annablume.

Resnick, M., Maloney, J., Monroy-Hernández, A., Rusk, N., Eastmond, E., Brennan, K., Millner, A., Rosenbaum, E., Silver, J. S., Silverman, B., et al. (2009). Scratch: Programming for all. Commun. Acm, 52(11):60-67.

Ribeiro, R. B., Fernandes, D., de Carvalho, L. S. G., and Oliveira, E. (2018). Gamificação de um Sistema de Juiz Online para Motivar Alunos em Disciplina de Programação Introdutória. In Brazilian Symposium on Computers in Education (Simpósio Brasileiro de Informática na Educação-SBIE), volume 29, page 805.

Sabino, E. (2014). Uso de Software de Interação no Ensino Fundamental: apoio à formação do aluno com monitorização e controle de processos educativos. Projetos e Dissertações em Sistemas de Informação e Gestão do Conhecimento, 3(2).

Santos, A. M., Júnior, M. F. S., and do Nascimento Lopes, E. R. (2016). Gamificando a Educação Ambiental: o desafio jogando verde no Instituto Federal Baiano. Revista Brasileira de Educação Ambiental (RevBEA), 11(1):245-263.

Souza Jr, E., Ribeiro, N. E. C., and Dazzi, R. L. S. (2009). Coleta Seletiva: Educação ambiental com webcam game. In VIII Brazilian Symposium on Games and Digital Entertainment. Rio de Janeiro-RJ, Brasil.

Wing, J. (2017). Computational thinking's influence on research and education for all. Italian Journal of Educational Technology, 25(2):7-14.

Wing, J. M. and Stanzione, D. (2016). Progress in computational thinking, and expanding the HPC community. Communications of the ACM, 59(7):10-11. 